\title{
Dysfunction in the fellow eyes of strabismic and anisometropic amblyopic children assessed by visually evoked potentials
}

\author{
Alterações dos potenciais visuais evocados nos olhos contralaterais de crianças \\ com ambliopia estrabísmica e anisometrópica
}

Eric Pinheiro Andrade ${ }^{1}$, Adriana Berezovsky ${ }^{1}$, Paula Yuri Sacal ${ }^{1}$, Josenilson Martins Pereira ${ }^{1}$, Daniel Martins Rocha ${ }^{1}$, Solange Rios Salomão ${ }^{1}$

\begin{abstract}
Purpose: To evaluate visual acuity and transient pattern reversal (PR) visual evoked potentials (VEPs) in the fellow eyes of children with strabismic and/or anisometropic amblyopia.

Methods: Children diagnosed with strabismic and/or anisometropic amblyopia were recruited for electrophysiological assessment by VEPS. Monocular grating and optotype acuity were measured using sweep-VEPs and an Early Treatment Diabetic Retinopathy Study chart, respectively. During the same visit, transient PR-VEPs of each eye were recorded using stimuli subtending with a visual angle of 60 ', 15', and 7.5'. Parameters of amplitude (in $\mu \mathrm{V}$ ) and latency (in ms) were determined from VEP recordings.

Results: A group of 40 strabismic and/or anisometropic amblyopic children (22 females: $55 \%$, mean age $=8.7 \pm 2.2$ years, median $=8$ years) was examined. A control group of 19 healthy children ( 13 females: $68.4 \%$, mean age $=8.2 \pm 2.6$ years, median $=8$ years) was also included. The fellow eyes of all amblyopes had significantly worse optotype acuity $(p=0.021)$ than the control group, regardless of whether they were strabismic $(p=0.040)$ or anisometropic $(p=0.048)$. Overall, grating acuity was significantly worse in the fellow eyes of amblyopes $(p=0.016)$ than in healthy controls. Statistically prolonged latency for visual angles of 15' and $7.5^{\prime}(p=0.018$ and 0.002 , respectively) was found in the strabismic group when compared with the control group. For the smaller visual stimulus $\left(7.5^{\prime}\right)$, statistically prolonged latency was found among all fellow eyes of amblyopic children $(p<0.001)$.

Conclusions: The fellow eyes of amblyopic children showed worse optotype and grating acuity, with subtle abnormalities in the PR-VEP detected as prolonged latencies for smaller size stimuli when compared with eyes of healthy children. These findings show the deleterious effects of amblyopia in several distinct visual functions, mainly those related to spatial vision.
\end{abstract}

Keywords: Visual acuity; Evoked potentials, visual; Electrophysiology; Amblyopia; Refractive errors; Child

\section{RESUMO}

Objetivo: Avaliar a acuidade visual e os potenciais visuais evocados transientes por reversão de padrões no olho contralateral de crianças com ambliopia estrabísmica elou anisometrópica.

Métodos: Foram avaliados os potenciais visuais evocados de crianças com ambliopia estrabísmica elou anisometrópica. As acuidades visuais monoculares de grades e de optotipos foram mensuradas utilizando o PVE de varredura e a tabela EDTRS, respectivamente. Na mesma visita, foram registrados os PVERP transients de cada olho usando estímulos de ângulo visual de 60'; 15' e 7,5' Parâmetros de amplitude (em microvolts) e latência (em milissegundos) foram determinados para os registros dos potenciais visuais evocados.

Resultados: Um grupo de 40 crianças amblíopes estrábicas e/ou anisometrópicas (22 meninas - 55\%, media idade $=8,7 \pm 2,2$, mediana $=8$ ) foi examinado. Um grupo de 19 crianças saudáveis (13 meninas 68,4\%, media idade $=8,2 \pm 2,6$, mediana $=8$ ) de controle também foi incluído. A acuidade visual por optotipos foi significativamente pior $(p=0,021)$ nos olhos contralaterais de todos os amblíopes, quando comparado com o grupo controle, independentemente se estrábico $(p=0,040)$ ou anisometrópico $(p=0,048)$. No geral, a acuidade visual por grades foi significativamente pior nos ol hos contralaterais dos ambliopes $(p=0,016)$, quando comparados com o grupo controle. Foi encontradalatência estatisticamente prolongada para ângulos visuais de $15^{\prime}(p=0,018)$ e $7,5^{\prime}(p=0,002)$ no grupo estrábico, quando comparado com o grupo controle. Para o menor estímulo visual $\left(7,5^{\prime}\right)$ foi encontrada latência estatisticamente prolongada nos olhos contralaterais de todas crianças amblíopes $(p<0,001)$.

Conclusões: Os olhos contralaterais de crianças amblíopes mostraram pior acuidade visual de optotipo e de resolução de grades, com alterações sutis nos PVERP, detectadas pelas latências prolongadas para estímulos de menor tamanho, quando comparados com os ol hos de crianças saudáveis. Estes resultados mostram os efeitos deletérios da ambliopia em várias funções visuais distintas, principalmente relacionadas à visão espacial.

Descritores: Acuidadevisual; Potenciais visuais evocados; Eletrofisiologia; Ambliopia; Erros de refração; Criança

\section{INTRODUCTION}

Amblyopia is a developmental disorder that occurs when the visual input from the two eyes is poorly correlated during early development. Such poor correlation may be due to a chronically blurred image in one eye (anisometropia), a turned eye (strabismus), or deprivation of one or both eyes ${ }^{(1)}$.

In anisometropic amblyopia, the connections between the retina and cortex do not form an accurate cortical topographic map, as in a normal subject, which results in widespread visual loss in the affected eye $e^{(2-4)}$. In strabismus, a new fixation point is formed mainly for esotropia and creates new connections with the visual cortex. As the density of retinal ganglion cells decreases and the center of receptive fields becomes larger as they move away from the fovea, visual acuity in this new setting is limited and the "good" eye image suppresses visualization by the eye with poorer acuity to avoid diplopia and generation of amblyopia(5)

Amblyopia onset usually occurs within the first 3 years of life and is thought to reflect alterations in the properties of neurons in early

Submitted for publication: January 12, 2016

Accepted for publication: May 30, 2016

Department of Opththalmology and Visual Sciences, Escola Paulista de Medicina (EPM), Universidade Federal de São Paulo (UNIFESP), São Paulo, SP, Brazil.

Funding: No specific financial support was received for this study.

Disclosure of potential conflicts of interest: None of the authors have any potential conflict of interest to disclose.

Corresponding author: Eric Pinheiro de Andrade. Rua Catão, 804/61 - São Paulo, SP - 05049-000 Brazil - E-mail: dr.eric.andrade@gmail.com

Approved by the following research ethics committee: Federal University of São Paulo (approval no 0503/08). 
cortical areas, possibly even as early as the lateral geniculate nucleus. Accordingly, sensory deficits include loss of visual acuity, stereopsis, position acuity, and contrast sensitivity, particularly at high spatial frequencies ${ }^{(6)}$.

Several different treatments have been proposed for amblyopia therapy over the last century. Of these, patching therapy has been used to treat amblyopia for several years, even though this therapeutic option has many shortcomings and compliance is poor because of the difficulty of forcing a child to wear a patch combined with the impaired vision experienced by the child when the patch is in place. Moreover, the use of full-time occlusion can cause psychophysical dysfunction in the fellow eye; therefore, partial occlusion is more beneficial ${ }^{(7)}$.

Physiological and electrophysiological parameters are markedly attenuated in the amblyopic eye, mainly the amplitude of small pattern elements of the transient pattern reversal visual evoked potentials (PR-VEPs). A small, but statistically significant, increase in the latency of the transient PR-VEP also occurs in the amblyopic eye ${ }^{(8)}$. While the amblyopic eye has been overly studied ${ }^{(2-11)}$ in children with strabismic and anisometropic amblyopia, there are few studies about the fellow eye ${ }^{(11-15)}$.

In the present study, the hypothesis that fellow eyes of children with amblyopia are not fully normal was tested by visual acuity measured behaviorally with an optotype chart, grating acuity measured electrophysiologically by sweep-VEP, and by assessment of the integrity of the maculo-occipital pathway tested by electrophysiological parameters of transient PR-VEP.

\section{METHODS}

The main outcome measures of this prospective cross-sectional observational study were optotype acuity, grating acuity, and PR-VEP parameters of amplitude and latency. The study protocol was approved by the Committee of Ethics in Research of the Federal University of São Paulo (approval number 0502/08) and conducted in accordance with the tenets of the Declaration of Helsinki, and informed consent was obtained from the parents of each child before testing.

Children with anisometropic and/or strabismic amblyopia who participated in the study were recruited from pediatric private practice and the Strabismus Section of the Department of Ophthalmology and Visual Sciences, Federal University of São Paulo. Inclusion criteria were a previous diagnosis of amblyopia by ophthalmic examination, inter-ocular acuity difference of at least two lines using the conventional printed Snellen chart, best optical correction, and normal fundus. Anisometropia was determined by one or more of the following: a difference of at least 1.00 diopter (D) in the spherical component; a difference of $0.75 \mathrm{D}$ in the cylindrical component; or a spherical equivalent difference of more than 1.50 D. The exclusion criteria were the presence of any other eye condition that could decrease visual acuity; any neurological disease; or a history of seizures or use of anti-seizure medication.

The type of occlusion therapy was noted for each participant as full-time (patching during all awake hours) or part-time (patching during part of awake hours), the eye to be patched (if alternate or not), and the compliance of the prescribed patching.

A comprehensive ophthalmic examination, which included an external eye examination, ocular motility assessment, biomicroscopy, cycloplegic refraction, and fundus assessment with indirect binocular ophthalmoscopy, was performed before electrophysiological testing by a pediatric ophthalmologist.

\section{Optotype acuity}

The optotype acuity of each eye was measured, with best optical correction, using an ETDRS "tumble E" retro-illuminated chart presented at a distance of $4 \mathrm{~m}$. Visual acuity scores are presented as the logarithmic minimum angle of resolution (logMAR).

\section{Grating acuity MEASURED by SWEeP VEPS}

Grating acuity of each eye was measured using the PowerDiva (digital infant vision assessment) sweep-VEP system developed by
Norcia and Tyler in 1999. The stimuli were phase-reversal sine-wave gratings presented on a $29 \times 38-\mathrm{cm}$, high-resolution, monochromatic, video monitor. The mean luminance was maintained at $140 \mathrm{~cd} / \mathrm{m}^{2}$ throughout the session. Responses were obtained from electroencephalogram (EEG) electrodes attached to the scalp with electrode cream and cotton pads.

The EEG was recorded from two bipolar placements positioned at $\mathrm{O}$, (left occiput) and $\mathrm{O}_{2}$ (right occiput), $2-3 \mathrm{~cm}$ to the left and right of a ground electrode placed $1 \mathrm{~cm}$ above the inion on the midline. A reference electrode was placed at the vertex $\left(C_{7}\right)$. Differences in electric potentials were amplified (gain=10,000; $-3 \mathrm{~dB}$ cutoff at 1 and $100 \mathrm{~Hz}$ ).

The stimuli were presented at a constant average luminance of 120.97 to $142.35 \mathrm{~cd} / \mathrm{m}^{2}$, contrast of $80 \%$, and temporal modulation rate of $6 \mathrm{~Hz}$ (12 reversals/s). The subject was positioned at a distance of 30 to $150 \mathrm{~cm}$ from the monitor (depending on the quality of fixation and age) and visual attention was drawn to small toys and objects shown in the center of the monitor.

Fixation was maintained during each trial with small toys presented hanging in front of the TV monitor and small music boxes to focus the infant's attention. When the subject was alert and fixated on the monitor (judged by the position of the image of the monitor centered in the subject's pupil), the observer began recording the EEG from two channels that were adaptively filtered (bandpass) in real time (sampling rate $=397 \mathrm{~Hz}$ ) to isolate the VEPs. The amplitude and phase of the first and second harmonics of the stimulus frequency were calculated for each channel. The test was performed in a dark room so that the primary cues for accommodation were provided by the display. Grating acuity was measured by sweeping spatial frequency at a fixed contrast of $80 \%$. Ten linearly-spaced spatial frequencies at $1 / \mathrm{s}$ were presented starting at a low spatial frequency. Patterns were temporally alternated in counterphase with a temporal modulation of $6.6 \mathrm{~Hz}$ for all tests.

Three to 12 repetitions of the sweep were obtained and the vectors were averaged. Grating acuity was estimated with an automated algorithm, which performs a linear fit and extrapolation to zero amplitude for the final descending limb of the function related to the VEPs in the second harmonic amplitude to the linear spatial frequency. A signal-to-noise ratio (SNR) at peak mean amplitude of 3:1 was required. In all cases, two thresholds (one for each channel) were obtained. The final acuity score was calculated in logMAR using the results of the better threshold channel with the highest SNR.

\section{PR-VEPS}

PR-VEPs of each eye were recorded with natural pupils and the participant using the best optical correction. During the examination, each patient remained comfortably seated and the scalp was cleaned with Nuprep ${ }^{\circledR}$ abrasive gel (DO Weaver \& Co., Aurora, CO, USA). Each channel was processed using gold disk electrodes (Grass Model F-E5GH; Astro-Med, Inc., West Warwick, RI, USA) that were placed according to the 10-20 system of electro-encephalography. One active electrode was placed $2 \mathrm{~cm}$ above the inion $\left(\mathrm{O}_{z}\right)$, a reference electrode was placed on the forehead (FP), and a ground electrode was placed at the vertex $\left(C_{7}\right)$. Each electrode was fixed in position with EC2 conductive paste (Ástro-Med, Inc.) and an elastic band.

The screen of the stimulator had a visual field of $17^{\circ} \times 17^{\circ}$ and consisted of a black and white checkerboard pattern with subtending visual angles of 7.5', 15', and 60'. The temporal frequency was set at $1.9 \mathrm{~Hz}$. Maximum contrast (100\%) and constant luminance were used. The occipital responses were recorded using the UTAS E-3000 system (LKC Technologies Inc., Gaithesburg, MD, USA). An average of 100 individual responses to the PR-VEPs were recorded from each eye. Latencies of the largest positive peak (P100) were determined in ms. Peak-to-peak amplitude was defined as the difference between the peaks of $\mathrm{N} 75$ and P100 in $\mu \mathrm{V}$. A representative PR-VEP waveform is shown in figure 1.

\section{Statistical analysis}

All statistical analyses were performed using Stata: Data Analysis and Statistical Software version 12 (StataCorp LP, College Station, TX, 


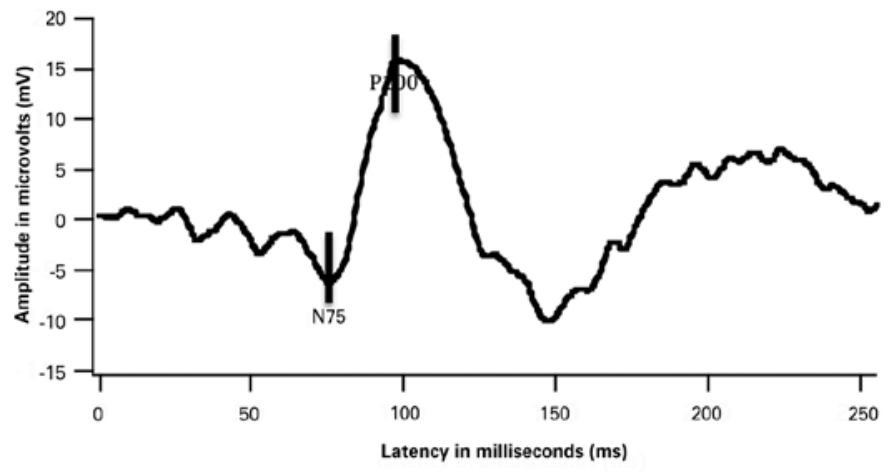

Figure 1. A representative transient PR-VEP waveform of a 9-year-old healthy girl.
USA). The following statistical models were used: the Student's t-test, one-way analysis of variance (ANOVA), the paired t-test, the Pearson correlation coefficient, and multiple linear regression analysis. When there was no normal distribution of variables, the nonparametric Mann-Whitney and Kruskal-Wallis ANOVA tests were used. A probability $(p)$ value of $\leq 0.05$ with a two-tailed rejection region, according to the common general pattern in medical and biological areas, was considered statistically significant.

\section{RESULTS}

A group of 40 amblyopic children, consisting of 18 boys (45\%) and 22 girls (55\%), was tested. The mean age of the children was $8.7 \pm 2.2$ (range, 6-14) years. Amblyopia was considered as strabismic in 21 (52.5\%) children, anisometropic in 15 (37.5\%), and a mix of both in four (10\%). The demographic and clinical features of these patients are shown in table 1. Full-time occlusion therapy of the fellow eye was

Table 1. Demographic and clinical features of amblyopic children

\begin{tabular}{|c|c|c|c|c|c|c|}
\hline ID & Gender & Age & Amblyopia group & Ocular motility & Refraction & Patching \\
\hline 1 & Female & 8 & Mix & Esotropia & OD: $-2.00-2.00 @ 010^{\circ}$ & Yes \\
\hline 2 & Male & 6 & Mix & Esotropia & OD: +3.00-0.00@ 000 & Yes \\
\hline 3 & Female & 7 & Mix & Esotropia & OD: +3.75 -0.00@ 000 & Yes \\
\hline 4 & Male & 12 & Mix & Esotropia & OD: +0.50 +0.75 @ 010 & Pretreat \\
\hline 5 & Female & 8 & Anisometropia & Orthoposition & OD:-1.50 -0.50@ @180 & No \\
\hline 6 & Male & 7 & Anisometropia & Orthoposition & OD: $0.00-2.00 @ 005^{\circ}$ & Yes \\
\hline 7 & Male & 10 & Anisometropia & Orthoposition & OD: +0.50 +0.25 @ 100 & Pretreat \\
\hline 8 & Female & 7 & Anisometropia & Orthoposition & OD: +1.50-2.00@10 & No \\
\hline 9 & Male & 7 & Anisometropia & Orthoposition & OD: +1.00 +0.50@ 170 & No \\
\hline 10 & Female & 9 & Anisometropia & Orthoposition & OD: +1.50-0.00@ 000 & No \\
\hline 11 & Male & 7 & Anisometropia & Orthoposition & OD: +1.50-0.00@ 000 & No \\
\hline 12 & Male & 7 & Anisometropia & Orthoposition & OD: +1.50-0.00@ 000 & No \\
\hline 13 & Female & 7 & Anisometropia & Orthoposition & OD: $-0.25-2.25 @ 005^{\circ}$ & No \\
\hline 14 & Female & 6 & Anisometropia & Orthoposition & OD: -10.50-3.00 @ 180 & Yes \\
\hline 15 & Female & 7 & Anisometropia & Orthoposition & OD: -6.50 -1.00 @ 035० & Yes \\
\hline 16 & Female & 9 & Anisometropia & Orthoposition & OD:-6.50 -5.50 @ 010 & Yes \\
\hline 17 & Male & 8 & Anisometropia & Orthoposition & OD:+2.00-0.00@ 000 & Yes \\
\hline 18 & Female & 9 & Anisometropia & Orthoposition & OD: +0.50-0.50@ @180 & Yes \\
\hline 19 & Female & 8 & Anisometropia & Orthoposition & OD: -1.00 -1.00 @ 180 & Pretreat \\
\hline 20 & Female & 10 & Strabismus & Esotropia & OD: +0.75 +0.50@ 180 & No \\
\hline 21 & Male & 12 & Strabismus & Esotropia & OD: +0.75 +0.75@090 & Pretreat \\
\hline 22 & Female & 7 & Strabismus & Esotropia & OD: +8.50-0.00@ 000 & Yes \\
\hline 23 & Male & 14 & Strabismus & Esotropia & OD: +1.50+1.00@180 & No \\
\hline 24 & Female & 7 & Strabismus & Exotropia & OD: +1.00-0.00@ 000 & Pretreat \\
\hline 25 & Female & 12 & Strabismus & Esotropia & OD: $0.00-1.00 @ 180^{\circ}$ & No \\
\hline 26 & Male & 8 & Strabismus & Esotropia & OD: +1.75 +1.25 @ 060 & Pretreat \\
\hline 27 & Male & 7 & Strabismus & Esotropia & OD: +1.00-0.00@ 000 & No \\
\hline 28 & Female & 7 & Strabismus & Esotropia & OD: +1.50 +0.75 @ 095 & No \\
\hline 29 & Male & 7 & Strabismus & Esotropia & OD: +4.50 +2.25 @ 0150 & No \\
\hline 30 & Female & 8 & Strabismus & Esotropia & OD: +4.75 +2.25 @ 110 & Pretreat \\
\hline 31 & Male & 8 & Strabismus & Esotropia & OD: +1.50-0.00@ 000 & Pretreat \\
\hline 32 & Male & 10 & Strabismus & Esotropia & OD: +6.00+1.00@ 950 & Yes \\
\hline 33 & Female & 9 & Strabismus & Exotropia & OD: +1.75-0.00@ 000 & Yes \\
\hline 34 & Female & 6 & Strabismus & Esotropia & OD: +3.50+0.75@100 & Yes \\
\hline 35 & Female & 13 & Strabismus & Esotropia & OD: +1.00-0.00@ 000 & Pretreat \\
\hline 36 & Female & 8 & Strabismus & Esotropia & OD: +2.00 +2.50@ 105 & Yes \\
\hline 37 & Male & 13 & Strabismus & Esotropia & OD: +2.25-3.75@ @1750 & Pretreat \\
\hline 38 & Male & 13 & Strabismus & Esotropia & OD: +0.75 -0.00@ 000 & No \\
\hline 39 & Male & 11 & Strabismus & Esotropia & OD: +0.75 -0.00@ 000 & Pretreat \\
\hline 40 & Female & 9 & Strabismus & Esotropia & OD: +4.25 +0.75 @ $075^{\circ}$ & Yes \\
\hline
\end{tabular}


ongoing in $15(37.5 \%)$ children at the time of examination, whereas $14(35.0 \%)$ children had never had previous patching therapy and 11 (27.5\%) have had it previously, but it had been discontinued before the examinations.

The control group consisted of 19 healthy children with normal ophthalmic exam results, consisting of six males (31.6\%) and $13 \mathrm{fe}-$ males (68.4\%) with a mean age of $8.2 \pm 2.6$ (range, $5-15)$ years. The demographic and clinical features of this group are shown in table 2 .

\section{Visual ACUITY}

\section{Optotype acuity}

Optotype acuity ranged from 0.00 (20/20) to 0.24 (20/34) logMAR in the fellow eye of amblyopic children and from 0.00 (20/20) to 0.00 (20/20) logMAR in those of the control group. Overall, optotype acuity was significantly worse $(p=0.021)$ in the fellow eyes of all amblyopic patients than in the control group $(0.04 \pm 0.07 \log M A R$, median 0.0 logMAR vs. $0.0 \pm 0.0 \log M A R$, median $0.0 \log M A R$, respectively). The same trend was found in the strabismic group $(p=0.040,0.04 \pm 0.08$ $\log M A R$, median $0.0 \log M A R)$ and the anisometropic group ( $p=0.048$, $0.04 \pm 0.07 \log M A R$, median $0.0 \log M A R$ ). Optotype acuity was significantly better in control eyes than in fellow eyes in the groups with and without occlusion therapy ( $p<0.05$, both).

\section{Grating acuity}

Grating acuity ranged from -0.01 (20/19) to 0.21 (20/32) logMAR in the fellow eyes of amblyopic children and from 0.01 (20/20) to 0.20 (20/31) logMAR in those of the control group. Grating acuity was also significantly worse $(p=0.016)$ in fellow eyes of all amblyopic subjects than in the control group $(0.07 \pm 0.05 \log M A R$, median 0.07 logMAR vs. $0.05 \pm 0.04 \log M A R$, median 0.05 logMAR, respectively). Regarding occlusion, the control group had significantly better optotype acuity than the fellow eyes in the group without occlusion $(p<0.05)$.

Figure 2 shows the individual scores of optotype (A) and grating acuity (B) for the fellow eyes of amblyopic children (filled symbols) and a randomly selected eye of the control group for optotype acuity

\section{Table 2. Demographic and clinical features of the control group}

\begin{tabular}{ccrcc}
\hline ID & Gender & Age & Ocular motility & Refraction \\
\hline 1 & Female & 8 & Orthophoria & OD: $+0.75-0.00 @ 000^{\circ}$ \\
2 & Male & 8 & Orthophoria & OD: $+1.25-0.00 @ 000^{\circ}$ \\
3 & Female & 5 & Orthophoria & OD: $+1.50-0.00 @ 000^{\circ}$ \\
4 & Female & 12 & Orthophoria & OD: $-2.25-0.00 @ 000^{\circ}$ \\
5 & Female & 7 & Orthophoria & OD: $+7.25+1.50 @ 100^{\circ}$ \\
6 & Male & 10 & Orthophoria & OD: $+5.25+2.75 @ 095^{\circ}$ \\
7 & Female & 9 & Orthophoria & OD: $+0.50-0.00 @ 000^{\circ}$ \\
8 & Female & 8 & Orthophoria & OD: $+1.75-0.00 @ 000^{\circ}$ \\
9 & Female & 7 & Orthophoria & OD: $+0.50+0.25 @ 060^{\circ}$ \\
10 & Male & 6 & Orthophoria & OD: $+1.00-0.00 @ 000^{\circ}$ \\
11 & Female & 7 & Orthophoria & OD: $+1.50-0.00 @ 000^{\circ}$ \\
12 & Female & 6 & Orthophoria & OD: $+1.00-0.00 @ 000^{\circ}$ \\
13 & Male & 8 & Orthophoria & OD: $+1.00-0.00 @ 000^{\circ}$ \\
14 & Female & 11 & Orthophoria & OD: $+0.75-0.00 @ 000^{\circ}$ \\
15 & Female & 5 & Orthophoria & OD: $+1.50-0.00 @ 000^{\circ}$ \\
16 & Male & 9 & Orthophoria & OD: $+1.50-3.00 @ 180^{\circ}$ \\
17 & Male & 5 & Orthophoria & OD: $+1.50-0.00 @ 000^{\circ}$ \\
18 & Female & 15 & Orthophoria & OD: $+0.50-0.00 @ 000^{\circ}$ \\
19 & Female & 10 & Orthophoria & OD: $+0.75-0.00 @ 000^{\circ}$ \\
\hline
\end{tabular}

$\mathrm{ID}=$ identification; $\mathrm{OD}=$ right eye; $\mathrm{OS}=$ left eye. and the eye with better vision of the control children (open symbols) for grating acuity.

\section{Pattern Reversal transient visually evoked potentials P100 latency}

There was a statistically prolonged latency of visual stimuli of $15^{\prime}$ ( $p=0.018,106.81 \pm 7.99 \mathrm{~ms}$, median $106.00 \mathrm{~ms})$ and $7.5^{\prime}(p=0.002,112.93$ $\pm 11.38 \mathrm{~ms}$, median $110.00 \mathrm{~ms}$ ) of the fellow eyes in the strabismic group, as compared to the control group $(101.42 \pm 5.46 \mathrm{~ms}$, median $102.50 \mathrm{~ms}$ for visual stimulus of 15', and $103.21 \pm 6.82 \mathrm{~ms}$, median $104.00 \mathrm{~ms}$ for visual stimulus of $7.5^{\prime}$ ). For the smaller visual stimulus, a statistically prolonged latency was also found in all amblyopic children ( $p<0.001$, $110.89 \pm 11.42 \mathrm{~ms}$, median $109.50 \mathrm{~ms}$ ) (Figures 3, 4, and 5).

Regarding occlusion, there was no statistically significant difference between control group and fellow eyes at 60' and $15^{\prime}$ compared to those with occlusion, without occlusion, and previously treated. The fellow eyes showed prolonged latencies for stimuli at $7.5^{\prime}$ in the group previously treated $(p<0.05)$, as compared to controls.

Comparing the N75-P100 amplitude of the fellow eyes with that of the control group, there were no differences between any stimuli and groups, including occlusion therapy.

\section{DISCUSSION}

For several decades, the fellow eye of amblyopic patients was considered unchanged due to presenting normal optotype acuity. An interesting finding of this study was that optotype acuity was worse in the fellow eyes of amblyopic patients than in those of healthy controls. These results were similar in patients with anisometropic amblyopia as well as strabismic amblyopia.
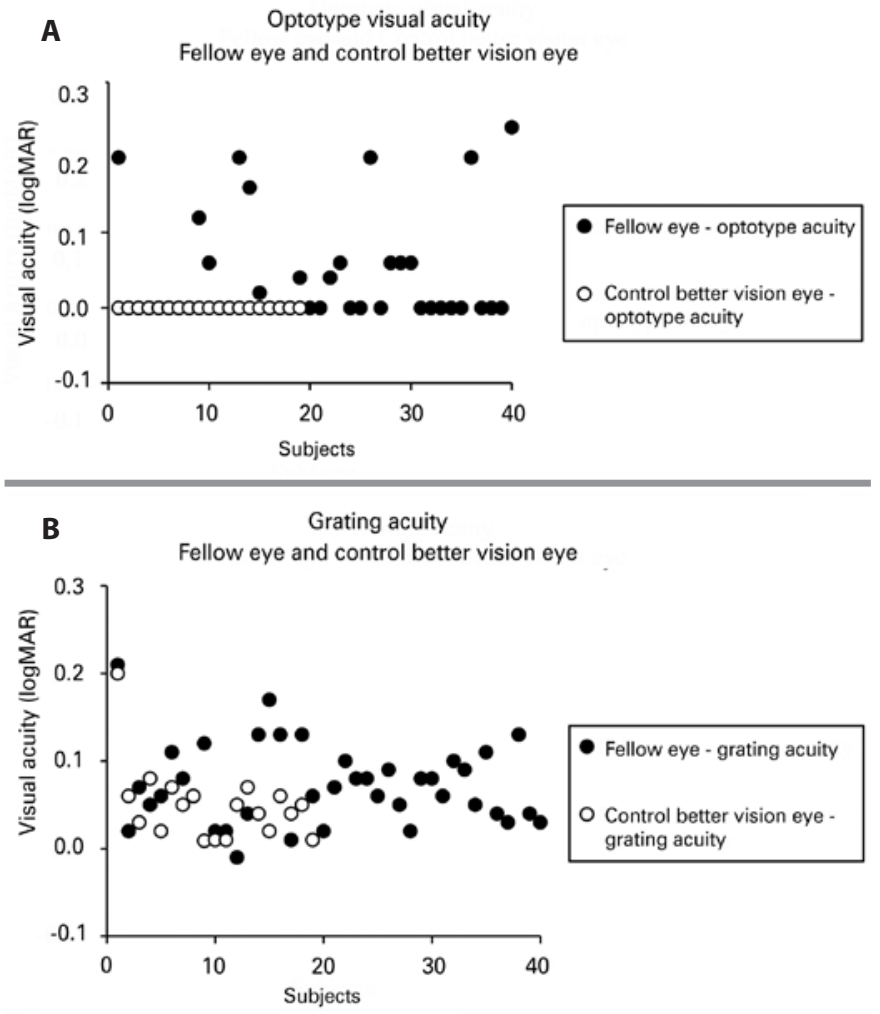

Figure 2. Individual scores of optotype (A) and grating acuity (B) of the fellow eyes of amblyopic children and the better-vision eye of control children. 


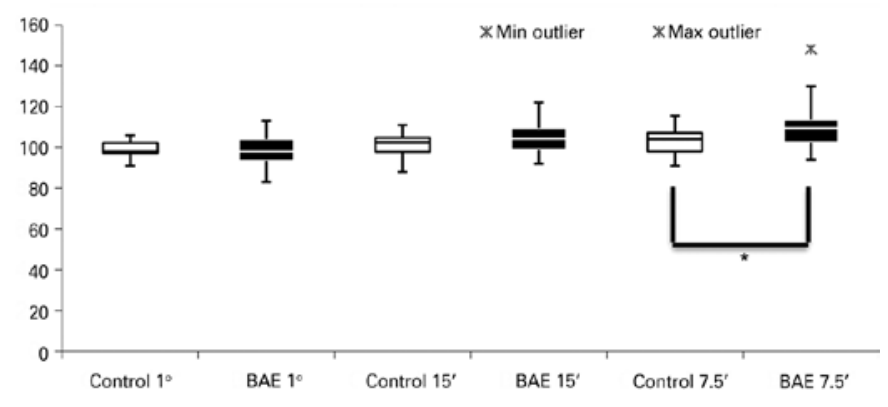

$\mathrm{BAE}=$ best acuity eye; ${ }^{*}=$ statistically significant difference.

Figure 3. P100 latency of the amblyopic group.

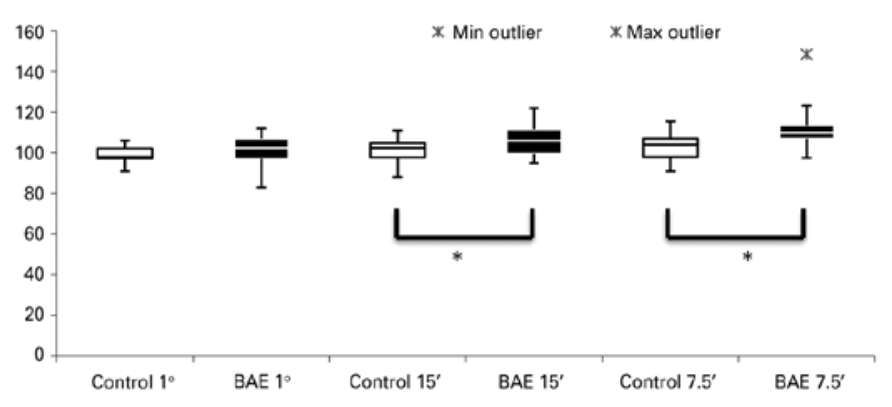

$\mathrm{BAE}=$ best acuity eye; ${ }^{*}=$ statistically significant difference.

Figure 4. P100 latency of the strabismic amblyopic group.

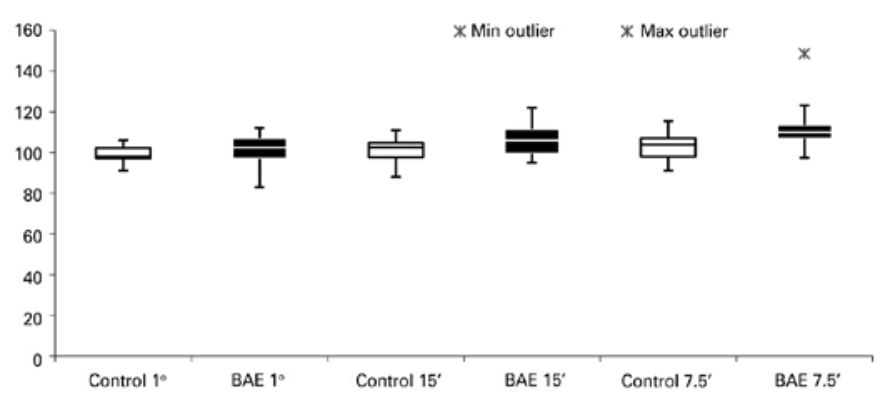

$\mathrm{BAE}=$ best acuity eye; ${ }^{*}=$ statistically significant difference.

Figure 5. P100 latency of the anisometropic amblyopic group.

Deficits in visual function of fellow eyes have been studied for more than three decades. Kandel et al..(13) unjustifiably classified the sound eye of amblyopic patients as normal based on the finding that these eyes have reduced contrast sensitivity, low visual acuity, and horizontal eccentric fixation when compared to normal eyes with normal binocular fixation.

A retrospective study evaluating visual acuity and the maturation of the fellow eye was conducted by reviewing the medical records of 112 children with unilateral amblyopia secondary to anisometropia, strabismus, or both conditions with previous patching therapy ${ }^{(11)}$. Corroborating the findings of this past study, the current study found statistically worse optotype acuity of the fellow eyes than of eyes of the control group, especially among patients with strabismic amblyopia.

Different results were observed when analyzing grating acuity, where the strabismic and anisometropic amblyopia groups showed similar results to the control group. However, when we analyzed the results of all amblyopes, significantly worse values were observed than those of the control group. The small patient cohort was a limitation to the present study, thus a larger sample of cases may provide different results.

Grating acuity may be overestimated by sweep VEP, especially with lower visual acuity ${ }^{(12)}$. By comparing the values of the contralateral eye of all amblyopes ( $N=40)$, we found statistically worse values than those of control group. This fact confirms the hypothesis that the fellow amblyopic eye is not completely normal. As indicated by the results of latency and amplitude of PR-VEPs of the fellow eyes in this study, only patients with strabismic amblyopia showed increased P100 latency for the smaller visual stimuli, as compared to the control group.

Although few studies have evaluated the parameters of PR-VEPS in the fellow eyes of patients with amblyopia, Mendonça et al. ${ }^{(16)}$ reported a case of mixed amblyopia in an 11-year-old child with delayed P100 latency in the amblyopic and fellow eyes to stimuli at 60', 30', and 15'. This finding was attributed to the loss of contrast sensitivity at high spatial frequencies, which can be intensified in anisometropic amblyopia.

However, patching therapy for amblyopia, particularly occluding the fellow eye, can have a negative effect, as shown in animal experiments, in which monocular deprivation has the greatest effect on the primary visual cortex rather than the retina and geniculate lateral body ${ }^{(13)}$. It is worthwhile to note that about one-third of the children in the current study were receiving patching therapy and another third had discontinued patching therapy. Occlusion, somehow, may have contributed to the results of the sound eye, especially in the parvocellular pathway.

When compared to healthy children, the fellow eyes of amblyopic children showed worse optotype and grating acuity, with subtle abnormalities in the PR-VEP detected as prolonged latencies for smaller size stimuli, especially in children with a history of therapy at the time of the exam. These findings confirm those of previous studies showing that the fellow eyes of amblyopic patients were not fully normal and patching therapy can cause physiological defects in sound eyes.

\section{REFERENCES}

1. Allen B, Spiegel DP, Thompson B, Pestilli F, Rokers B. Altered white matter in early visual pathways of humans with amblyopia. Vision Res. 2015;114:48-55.

2. Kiorpes L, Kiper DC, O'Keefe LP, Cavanaugh JR, Movshon JA. Neuronal correlates of amblyopia in the visual cortex of macaque monkeys with experimental strabismus and anisometropia. J Neurosci. 1998;18(16):6411-24.

3. Kiorpes L, McKee SP. Neural mechanisms underlying amblyopia. Curr Opin Neurobiol. 1999;9(4):480-6.

4. Birch EE. Amblyopia and binocular vision. Progr Retin Eye Res. 2013;33:67-84.

5. Daw NW. Visual development. New York: Spring Science; 2006.

6. Levi DM, Knill DC, Bavelier D. Stereopsis and amblyopia: a mini-review. Vision Res. 2015;114:17-30.

7. Mendonça RH, Abbruzzese S, Bagolini B, Nofroni I, Ferreira EL, Odom JV. Visual evoked potential importance in the complex mechanism of amblyopia. Int Ophthalmol. 2013; 33(5):515-9.

8. Oner A, Coskun M, Evereklioglu C, Dogan H. Pattern VEP is a useful technique in monitoring the effectiveness of occlusion therapy in amblyopic eyes under occlusion therapy. Doc Ophthalmol. 2004;109(3):223-7.

9. Hess RF, Thompson B. Amblyopia and the binocular approach toits therapy. Vision Res. 2015;114:4-16.

10. Sokol S. Abnormal evoked potential latencies in amblyopia. Br J Ophthalmol. 1983;67(5): 310-4.

11. Brémond-Gignac D, Copin H, Lapillonne A, Milazzo S, European Network of Study and Research in Eye Development. Visual development in infants: physiological and pathological mechanisms. Curr Opin Ophthalmol. 2011;22(1):S1-S8.

12. Ridder IIIWH, Rouse MW. Predicting potencials acuities in amblyopes. Doc Ophthalmol. 2007;114(4):135-45.

13. Kandel GL, Grattan PE, Bedell HE. Are the dominant eyes of amblyopes normal? Am J Optom Physiol Opt. 1980;57(1):1-6.

14. Varadharajan S, Hussaindeen JR. Visual acuity deficits in the fellow eyes of children with unilateral amblyopia. J AAPOS. 2012;16(1):41-5.

15. Leguire LE, Rogers GL, Bremer DL. Amblyopia: The normal eye is not normal. J Pediatr Ophthalmol Strabismus. 1990;27(1): 32-8.

16. Mendonça RH, Ferreira EL. Visual evoked potentials (VEP) and visual acuity improvement after cytidine 52-diphosphocholine (CDP-Choline) therapy in amblyopic patient. Rev Bras Oftalmol. 2012:71(5):328-30. 